\title{
Reflections on Irish management research: Past, present and future
}

\author{
David G. Collings ${ }^{1}$, James Cunningham², Geoffrey Wood ${ }^{3}$
}

${ }^{1}$ DCU Business School, Dublin City University, Dublin 9, Ireland

${ }^{2}$ Newcastle Business School, Northumbria University,

Newcastle Upon Tyne, United Kingdom

${ }^{3}$ Business School, University of Essex, Wivenhoe Park, Colchester,

C04 3SQ, United Kingdom

\section{Introduction}

The papers in this special issue were commissioned to reflect on the status of management research in Ireland as the Irish Journal of Management entered its fourth decade of publication. The special issue is intended to reflect on the current state of management research in Ireland and in so doing, consider its past and outline some future research directions. Drawing on some of the leading national contributors in their respective disciplinary fields, the special issue evaluates the research traditions and future trajectory of management research across the disciplines that have dominated the research published in the Irish Journal of Management over its history.

We invited contributions based around those topics that have been most strongly represented in the journal over the past three decades. ${ }^{1}$ For each contribution, we provided the authorial team with a rather broad brief to (1) outline the manner in which the study of the area has evolved; (2) consider the dominant theoretical traditions in the respective field; (3) discuss the key current issues and debates; (4) consider the consequences of recent socioeconomic change and crisis for the understanding of the area; (5) outline some key aspects of a research agenda in the field moving forward. However, in seeking these contributions, we did recognise the differing traditions of each disciplinary area, and hence, authors were afforded considerable freedom in terms of the focus of individual contributions.

Over the past four decades, the research focus and structures of Irish business schools have evolved significantly in line with national and international demands and trends. Irish management practice has been greatly influenced by foreign-owned multinational corporations (MNCs) located in Ireland and the growth of key sectors such as life sciences and information and communications technology (ICT) (Lavelle et al., 2009). From an international perspective, Irish management research output has grown. Evidence from the Forfás (2009) study highlighted the growth of output of research in the category of management studies concluding that 'Ireland shows strong growth (73\% increase in 2007 compared with the average 2002-06) in terms of business research publications. This headline figure needs to be interpreted carefully however, in the context of firstly a very low baseline (67 papers in 1998; 71 average 2002-06), and secondly a possibly aberrant figure for 2007.' Irish input as a proportion of the international output also increased dramatically (by $44 \%$ ). This places Ireland in $17^{\text {th }}$ position globally, moving ahead of the Czech Republic in the international rankings. Some of this growth in output has been supported by public research funding under the Higher Education Authority's Programme for Research in Third-Level Institutions

\footnotetext{
1 We were unable to commission a review on marketing research which we would also consider an area with an important tradition in the IJM. On three separate occasions, papers were commissioned and following a period of time were withdrawn. Ultimately, we made the decision to progress with publication in order to prevent further delay in publishing the reminder of the issue.
} 
(Cycles 1 to 5), and funding for the Irish Research Council for the Humanities and Social Sciences (now the Irish Research Council) and have been shaped by the growth of business schools across the Irish HEI sector'.

From a policy perspective, the importance of good management practice has been emphasised in the work of the Management Development Council. The Management Development Council (2010, p. 5) recommended a greater support for the third-level sector, state funding and regular research that shares best practices. Moreover, the Council estimated that improvements in management performance of small and medium enterprises (SMEs) could return up $€ 2.5$ billion to the economy to turnover/sales. Moreover, Professor Frank Roche, Chairman of the Management Development Council in 2010, in his foreword for the Management Development in Ireland report argued that

' ... Ireland requires a national system for management development. Such a system would see a diverse range of providers offering management programmes which utilize best international practice, in terms of both delivery and content, and which are designed to explicitly meet the needs of the enterprise sector.'

Our special issue is timely in an age where the academy is subject to scrutiny from international rankings at an institutional level (see Times Higher, QES) and where academic journals are regularly ranked and prioritised (Chartered Association of Business Schools and Australian Business Dean's Council) and indeed even individual business schools (Tol, 2012) and academics (Tol, 2010) ranked. Whilst each of these ranking mechanisms has its critics (Geary et al., 2004; Mingers and Willmott, 2012; Rafols et al., 2012; Hussain, 2015), there is little doubt that the rankings are beginning to have some impact on Business Schools and at a public policy level.

\section{Some drivers shaping management research}

When considering the future of management research, there are several drivers that are shaping research directions across management research domains. First is the relevance of management research to practice. A constant issue that management researchers are faced with is the relevance of their research to managers and leaders across different organizational settings in the public, private and third sectors? This continues to be a fundamental issue for management researchers. Managers are dealing with increasing levels of organisational complexities and rapidly changing external environmental. Therefore, managers need new approaches, perspectives and insights that are informed by scientifically rigorous management research in order to manage effectively. Intertwined with the relevance of management research is that researchers have to be conscious of the impact they have on management practice. Ghoshal (2005) has challenged researchers in this regard arguing: ' ...that academic research related to the conduct of business and management has had some very significant and negative influences on the practice of management. These influences have been less at the level of adoption of a particular theory and more at the incorporation, within the worldview of managers, of a set of ideas and assumptions that have come to dominate much of management research.'In essence management, researchers have a moral responsibility in this regard.

Second, a contemporary trend that is shaping management research is the impact that is linked to the relevance debate. The research evaluation framework (REF) in the United Kingdom placed an increasing emphasis on research impact as one of the evaluation criteria. The REF system requires business schools to submit research outputs, impacts template and cases (REF, 2014). This is considered a litmus test of the extent to which managers or an industry sector have adopted management research findings in practice. Impact is more than just sharing and disseminating management research findings with practitioner audiences through seminars and workshops. It is about how industry and other stakeholders are using this knowledge in the daily art of managing. This has implications for business schools in deciding what management research themes to prioritise, which will amplify scientific excellence as evidenced by traditional outputs as well as influencing management practice in real, tangible and measurable ways. For individual management researchers, a dual strategy of planning for scientific and management practice impact will become the norm. Ultimately, it is management researchers who will shape these impact norms as argued by London School of Economics Public Policy Group (2008) who recommended that it is 'The learned societies and individual discipline bodies across the HSS [humanities and social sciences] groupings should be the key actors for recording impacts on economic development, public policy, civil society and culture within an agreed common framework of measures. The individual academic professions best understand their own 
discipline and they can secure most buy-in from their members.' Impact is also shaping business school strategies of how to engage and collaborate with businesses and managers in a more effective and sustainable ways. Responses to this trend include the creation of knowledge transfer positions as part of business school management teams, and more aggressive social media campaigns to disseminate research results and engagement with business stakeholders. Moreover, we are also witnessing a trend in which funding agencies nationally and internationally are now seeking applicants to outline the wider impacts of their proposed research projects.

Third is fundamentally interrogating what is the purpose of management and how this shapes the design and themes of future management research. Debates continue within the literature regarding the purpose of management between maximising shareholder returns on the one side and balancing different stakeholders demands on the other. Moreover, examples of managerial failure abound across different sectors, and this has lessened society's trust in management researchers. To respond to this, Khurana and Nohria (2008) suggested a middle path that encompasses: 'the value-creating impetus of shareholder value concept and the accountability inherent in the stakeholder approach.' Management researchers similar to any other citizens or researchers are influenced by ideology, and this informs their individual research agenda and scholarship contributions. Greater articulation of such ideologies will further shape the debate on what is the purpose of management, one of the most fundamental questions that all management researchers should contribute to through their individual research agendas. This also requires an openness of mindset to broadening out the methodological approaches used to study management practice and managers. In doing so, methodological rigor needs to be maintained and not diluted. Engaged scholarship as advocated by Van de Ven (2007) not alone addresses rigor, relevance and impact but becomes a way of conducting management research that deals with the increasing pressures that management researchers face. Brannick and Coghlan (2006) put it succinctly in discussing academic researcher and practitioner knowledge: 'that an all-compassing view of research, which comprises individual inquiry and learning, collaborative inquiry and the generation of theory for broader audiences, is one which can underpin collaboration between academics and practitioners, as well as action research.'

Fourth, the availability of funding specifically dedicated to management research will shape the type management research that will be conducted by researchers and the methods used. The Advanced Institute of Management initiative in the United Kingdom demonstrated what can be accomplished to advance managerial knowledge and the impact on management practice. The challenge for management research and the academy is how to organise effectively to secure dedicated funding for management researchers to pursue rigorous and relevant research from the public research budget.

\section{The papers in this issue}

The objective of the special issue is not primarily to rank and evaluate scholarship but rather to provide a high-level overview of the evolution of academic study in the various disciplines under consideration, to reflect on the present state of affairs and to provide some insights into likely future directions.

Our first paper by Colm O'Gorman on the Study of Entrepreneurship in Ireland addresses a theme that is of national significance and importance. In doing so, O'Gorman assesses the impact of entrepreneurial research on academia, policy, practice and students. The paper reflects on the earlier Irish studies of entrepreneurship, discusses the impact of this research as well as exploring reasons why the practice of entrepreneurship is disconnected with research and teaching. One of the arguments in the paper is whilst a body of entrepreneurship literature has developed in an Irish context that has contributed to our understanding of entrepreneurship, it has not had significant international impact.

In the second paper in the issue Patrick Gibbons, Pamela Sharkey Scott and Cormac Mac Fhionnlaoich provide 'A perspective on the development of the field of strategic management and the contribution of the Irish Journal of Management'. Gibbons and colleagues analyse the evolution of the field of strategic management through tracing the papers awarded the Strategic Management Society Best Paper Award by the Strategic Management Journal $(\mathrm{SMJ})$ as reflective of the leading scholarship in the field. They map the development of the discipline from its market based and structural roots to attempts to decipher the 'black box' of the organisation in analysing capabilities, particularly dynamic capabilities, and resources. Through their review of SMJ and the Irish Journal of Management, they conclude that despite increasing market, social and cultural instability since these seminal papers were first conceived, their lessons are still relevant and increasingly critical to both theory and practice in establishing the 
future trajectory for strategic management and a framework for organisations to compete.

Our third paper, authored by Ronan Carbery, Patrick Gunnigle and Michael Morley considers research traditions and output in human resource management (HRM) in the Irish context. They begin by providing an overview of the key developments in HRM at institutional and practice levels in Ireland. They then consider how these impacted on curriculum, education and research advancements in the field. Carbery et al. then conducted a review of published papers between 1950 and 2010, which yielded some 195 academic papers. Their analysis of this output points to the changing profile of research on HRM in Ireland and provides some rich insights into the changing nature of HRM research there.

In the fourth and final paper in the special issue, Changing Time for Management Educators: Rethinking Engagement with Participatory forms of Knowledge Production, Denis Harrington, Briga Hynes and Jeremy Short explore how academic knowledge can be bridged with practice through participatory modes. Within the paper, they discuss the challenges facing management educators and the academic practitioner interface. The authors make an argument for the need for business schools to have activities that are aligned to practice-based interventions. The conclusions of this paper have policy implications as to how this could be achieved in an Irish context, given the current policy direction set by the HEA.

\section{Conclusions}

One constant that remains about the past, present and future of management research is the need for strong theoretical foundations. As we can see from this special issue, much has been achieved and Irish management researchers have contributed to shaping some of these theoretical foundations. The need for management researchers to maintain research rigour that contributes to knowledge development and holds up to the scrutiny and questioning of management practice is a core principle for management researchers to maintain credibility and trust of the management profession and society. For Irish management researchers, opportunity abound to be at the core of theory development, and this requires a consistency of focus coupled with optimising research supports. Moreover, we would argue that there is even a greater need for Irish management researchers to contribute to societal debates focused on our economy and society in a post bail out scenario. The mutual dependence, appreciation and trust between Irish management researchers and managers needs to be acknowledged, supported and grown through HEl business schools. This ultimately increases the scientific impact of Irish management researchers in increasingly competitive international arenas and the supports the efforts of Irish managers in dealing with the organisational and competitive complexities in a small open economy.

\section{References}

Brannick, T. and Coghlan, D. (2006) To Know and to Do: Academics' and Practitioners' Approaches to Management Research, Irish Journal of Management, 26(2), pp. 1-22.

Forfás (2009) Research Strengths in Ireland: A Bibliometric Study of the Public Research Base, Extension Report: Public Research Organisations. Dublin, Ireland.

Geary, J., Marriott, L. and Rowlinson, M. (2004). Journal Rankings in Business and Management and the 2001 Research Assessment Exercise in the UK, British Journal of Management, 15(2), pp. 95-141.

Ghoshal, S. (2005) Bad Management Theories are Destroying Good Management Practices,
Academy of Management Learning and Education, 4(1), pp. 75-91.

Hussain, S. (2015) Journal list fetishism and the 'sign of 4 ' in the ABS guide: A question of trust?, Organization, 22(1), pp. 119-138.

Khurana, R. and Nohria, N. (2008) It's Time to Make Management a True Profession, Harvard Business Review, 86(10), pp. 70-77.

Lavelle, J., McDonnell, A. and Gunnigle, P. (2009) (eds.) Human Resource Practices in Multinational Companies in Ireland: A contemporary analysis. Dublin: Government Publications Office.

LSE (London School of Economics) Public Policy Group (2008) Maximising the Social, Policy and Economic Impacts of Research in Humanities and 
Social Sciences, Report to the British Academy, London.

Mingers, J. and Willmott, H. (2012) Taylorizing Business School Research: On The 'One Best Way' Performative Effects of Journal Ranking Lists, Human Relations, 66(8), pp. 1051-1073.

Rafols, I., Leydesdorff, L., O'Hare, A., Nightingale, P. and Stirling, A. (2012) How Journal Rankings Can Suppress Interdisciplinary Research: A Comparison Between Innovation Studies and Business \& Management. Research Policy, 41(7), pp. 1262-1282.
REF (2014) Assessment Framework and Guidance on Submission, http://www.ref.ac.uk/about/guidance/ (Accessed on 29 September 2015).

The Management Development Council (2010) Management Development in Ireland: The Report of the Management Development Council, Dublin.

Tol, R.S.J. (2010) The research output of business schools and business scholars in Ireland. ESRI Working Paper, No. 364. Dublin, ESRI.

Tol, R.S.J. (2012) Shapley Values for Assessing Research Production and Impact of Schools and Scholars. Scientometrics, 90 (3), pp. 763-780. 